\title{
PERFORMA STRATEGI DCMA: STUDI SIMULASI
}

\author{
Bagus Manunggal \\ Fakultas Ekonomi dan Bisnis \\ Universitas Islam Syekh Yusuf Tangerang \\ bagusmanunggal@unis.ac.id \\ Yudi Priambodo PS \\ Vice President PT Bank Rakyat Indonesia (Persero) Tbk \\ yudi_pps@yahoo.com \\ DOI: https://doi.org/10.33592/jeb.v26i1.619
}

\begin{abstract}
Investors benefit from investing in the stock market, apart from dividends also obtained from capital gains. Through this study, the authors want to show that technical analysis can be used by investors to benefit from capital gains. To prove this, the author uses a trading simulation research method with AMRT stock price data with a time span of January 2015 to December 2019 and a daily period. The author uses the DMAC strategy, namely two Simple Moving Average with periods of 10 and 20. Crossing of the two high schools from the bottom up is used as an incoming signal, and crossing from the top down is used as an exit signal. With a capital simulation of Rp. 100000 and 1 lot per transaction, the results show that this strategy generates profit but is smaller than the growth of AMRT for 5 years.
\end{abstract}

Keywords: Capital Gain, Technical Analysis, Double Moving Average Cross.

\begin{abstract}
Abstrak
Keuntungan investor dari investasi di pasar saham, selain dari dividen juga diperoleh dari capital gain. Melalui penelitian ini, penulis ingin menunjukkan bahwa analisa teknikal dapat digunakan investor untuk mendapat keuntungan dari capital gain. Sebagai cara membuktikan hal tersebut, penulis menggunakan metode penelitian simulasi trading dengan data harga saham AMRT dengan rentang waktu Januari 2015 sampai dengan Desember 2019 dan periode harian. Penulis menggunakan strategi DMAC, yaitu dua Simple Moving Average dengan periode 10 dan 20. Crossing kedua SMA tersebut dari bawah keatas digunakan sebagai sinyal masuk, dan crossing dari atas ke bawah digunakan sebagai sinyal keluar. Dengan simulasi modal Rp 100000 dan 1 lot per transaksi, diperoleh hasil bahwa strategi ini menghasilkan profit namun lebih kecil disbanding dengan pertumbuhan AMRT selama 5 tahun.
\end{abstract}

Kata kunci: Capital Gain, Analisa Teknikal, Double Moving Average Cross. 


\section{A. Pendahuluan}

Alfamart tergolong emiten yang rajin membagi deviden. Berdasarkan data investing.com, sejak tahun 2015 hingga tahun 2020 emiten dengan kode AMRT ini telah 7 kali membagi deviden. Bahkan pada tahun 2018, AMRT membagi deviden hingga 2 kali, pada pertengahan tahun dan akhir tahun (investing.com, 2020).

Rata-rata deviden yield 5 tahun AMRT juga cukup menggiurkan mencapai $0.74 \%$. Yield yang cukup menggiurkan dan frekuensi bagi deviden yang rutin membuat AMRT layak untuk dikoleksi dalam portofolio (investing.com, 2020).

Namun seperti diketahui bersama, dalam berinvestasi di saham, keuntungan investor tidak hanya dari hasil deviden. Tapi juga selisih harga jual dan beli, atau yang kita sebut dengan capital gain (Mladjenovic, 2016).

Mengincar keuntungan dari capital gain tidak mudah (Prayudha, 2018). Investor harus memahami analisa teknikal harga saham, tidak cukup hanya memahami analisa fundamental. Mengingat analisa fundamental hanya untuk mengetahui kesehatan emiten, tidak mampu untuk menentukan trend dan memberikan sinyal buy atau sell (Rockefeller, 2014).
Hasil penelusuran penulis, banyak sekali penelitian mengenai anteseden harga saham dari sisi fundamental namun jarang yang membahas dari sisi teknikal. Berkenaan dengan hal tersebut, penelitian ini ingin menunjukkan bahwa dengan analisa teknikal sederhana, investor dapat meraup keuntungan dari selisih harga jualbeli.

\section{B. Review Literatur}

\section{a. Investasi Saham}

Terdapat dua keuntungan yang diperoleh investor saham, yaitu deviden dan selisih harga beli dan jual (capital gain) (Dechow, 2001). Deviden dibagikan pada investor tergantung dari hasil keputusan pada Rapat Umum Pemegang Saham (Deni Sunaryo, 2019). Sedangkan untuk memperoleh capital gain, seperti halnya perdagangan investor harus cermat untuk membeli saham di harga murah dan menjual saat harga cukup tinggi.

\section{b. Analisa Harga Saham}

Investor dapat menggunakan dua analisa untuk mengambil keputusan berinvestasi di pasar saham, yaitu analisa fundamental dan analisa teknikal (Tandelilin, 2010).

Analisa fundamental memperhitungkan factor makro dan mikro suatu emiten yang akan dipilih investor. Dimulai dari analisa ekonomi secara umum, analisa sector industri, hingga 
analisa kinerja berdasarkan laporan keuangan emiten tersebut. Tahapan tersebut membuat analisa fundamental disebut juga sebagai analisa top-down. Investor yang menggunakan analisa fundamental biasa disebut fundamentalist (Stewart, 1996). Fundamentalist berpandangan bahwa perusahaanakan berkembang pada lingkungan yang mendukung. Analisa ini membantu investor mengetahui potensi perkembangan emiten yang dipilih (Abarbanell \& Bushee, 1997).

Analisa teknikal mempelajari pergerakan harga untuk memprediksi pergerakan harga berikutnya. Investor yang menggunakan analisa teknikal biasa disebut technicalist (Bagus W., 2007). Dalam mengambil keputusan untuk investasi, technicalis tmempelajari tren hargasaham yang sedang berlangsung, memperhatikan indikator-indikator teknikal, hingga membaca pola-pola OHLC (Open High Low Close) harga yang terbentuk. Semua itu dilakukan untuk menentukanwaktu dan harga yang tepat untuk masuk dan keluar pasar saham (Rockefeller, 2014).

\section{c. Moving Average}

Moving Average merupakan indikator yang biasa digunakan investor untuk menentukan tren harga dan supportresistance (Kilgallen, 2012). Indikator ini memperhitungkan rata-rata harga, umumnya harga close, tiap periode waktu yang ditentukan oleh investor dan diplot dalam grafik (Finnerty et al., 2012).

Diantara beberapa jenis moving average, yang paling umum adalah Simple Moving Average .Secara umum, rumus dari adalah simple moving average adalah:

$S M A(t, N)=\frac{\sum_{k=1}^{N} P c(t-k)}{N}$

Dimana:

$\mathrm{N}$ = periode moving average

$\mathrm{Pc}=$ hargapenutupan

(Picasso et al., 2019)

\section{d. Double Moving Average Cross}

Penggunaan dua indicator moving average dengan periode berbeda (double moving average) dapat membantu investor untuklebih mudah membaca arah pergerakan dan pembalikan tren harga. Investor umumnya mengetahui tren dengan melihatarah kedua moving average tersebut. Bila moving average dengan periode yang lebih kecil di atas moving average dengan periode yang lebih besar dan arah kedua moving average tersebut mengarah ke atas, mengindikasikan tren harga naik. Sehingga investor hanya berfokus pada transaksi beli. Sebaliknya, jika indicator moving average dengan periode kecil berada di bawah moving average yang periode besar, dan keduanya mengarah kebawah, mengindikasikan tren 
harga sedang turun. Sehingga investor dapat wait and see untuk harga rebound (Murphy, 1999).

Sedangkan bila moving average periode kecil memotong moving average yang periode besar dari bawah ke atas, disebut juga crossing up, mengindikasikan terjadi pembalikan tren harga dari tren turun (bearish) ke tren naik (bullish). Serta sebaliknya, bila indicator moving average bersilangan dari atas kebawah, disebut juga crossing down, maka tren harga mulai berbalikdari bullish ke bearish (Lim, 2015).

\section{Metode Penelitian}

Pada penelitian ini, penulis berfokus hanya pada saham AMRT. Data harga OHLC (Open High Low Closs) diperoleh dari investing.com. Periode data yang digunakan adalah harian.Rentang data yang digunakan mulai dari 01 Januari 2015 hingga 31 Desember 2019.

Metode penelitian yang digunakan oleh penulis adalah simulasi, yaitu penulis melakukan simulasi trading dengan data OHLC yang diperoleh untuk menghasilkan sinyal beli dan jual. Berdasarkan data sinyal beli dan jual tersebut kemudian penulis melakukan simulasi jual-beli (trading) dengan pembelian per transaksi 1 lot (100 lembar) dan modal awal Rp100000. Portofolio hasil trading tersebut kemudian direkapitulasi dan diplot ke dalam grafik. Keseluruhan simulasi tersebut penulis lakukan pada Microsoft Excel.

Simulasi trading ini menggunakan strategi DMAC (Double Moving Averange Cross). Strategi DMAC dipilih karena penulis focus pada strategi yang sederhana agar mudah dipahami dan digunakan oleh investor pemula sekalipun. Periode moving average (MA) yang digunakan adalah periode 10 dan 20 hari. Sinyal beli diperoleh dari persilangan MA10 dengan MA20 dari bawah. Sedangkan sinyal jual diperoleh dari persilangan MA10 dengan MA20 dari atas.

Setelah dilakukan simulasi trading, penulis membandingkan profit yang diperoleh dari strategi tersebut dengan pertumbuhan harga saham AMRT selama Januari 2015 hingga Desember 2019

\section{Hasil Penelitian dan Pembahasan}

Data historis harga saham AMRT yang didapat dari investing.com dengan rentang waktu Januari 2015 - Desember 2019 dan periode harian mencapai 1195 baris data.

Pada Januari 2015 dibuka pada harga Rp 490. Sedangkan pada Desember 2019 ditutup di harga Rp 880. Selama jangka waktu tersebut, harga saham tertinggi menyentuh $\mathrm{Rp} 1080$ (+120.4\% atau +590 poin) pada Mei 2019. Sedangkan terendahnya mencapai Rp450 
(-8.16\% atau-40 poin) pada Maret 2015.

$79.59 \%$ (390 poin) selama 5 tahun.

Secara keseluruhan terdapat peningkatan

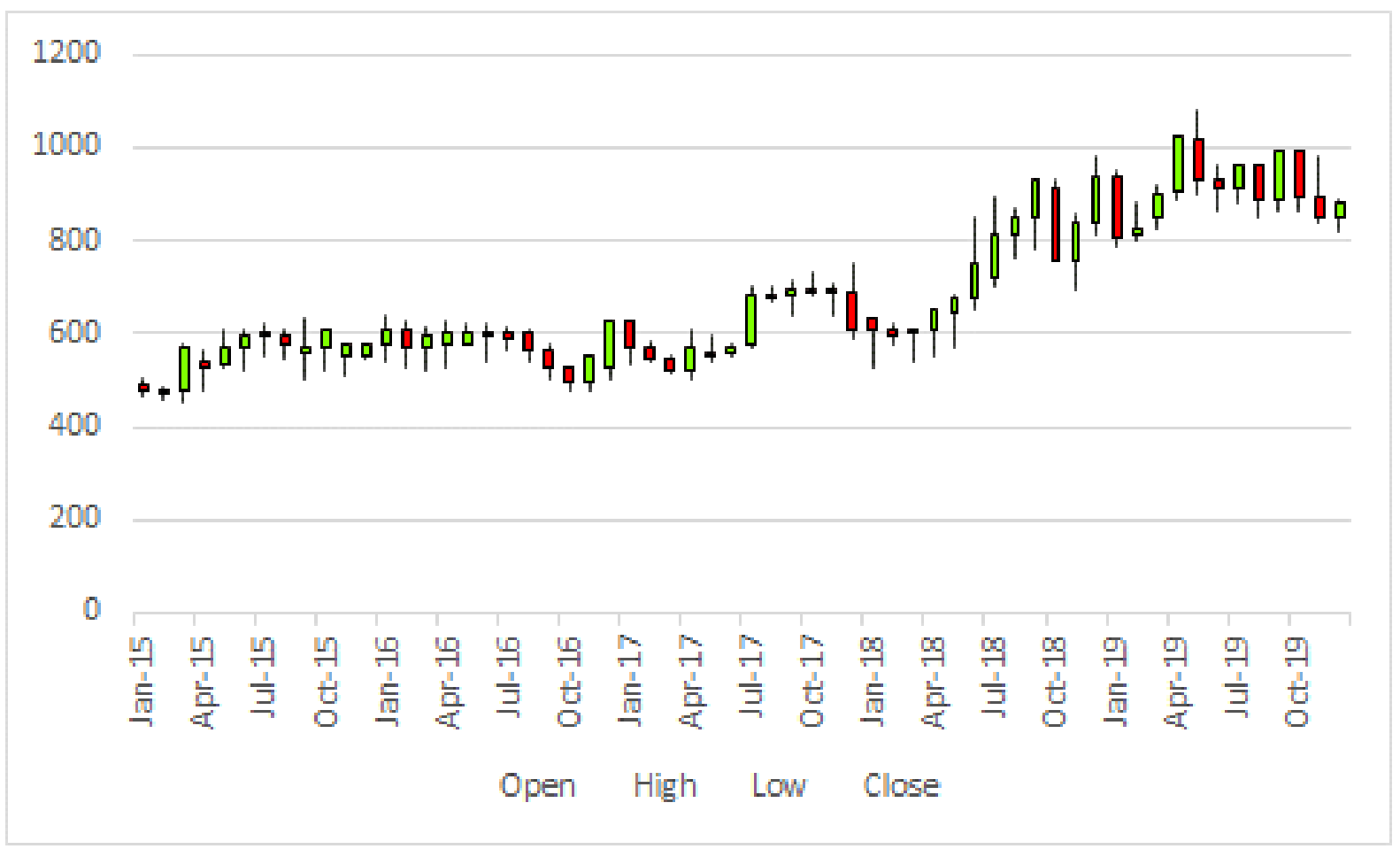

\section{Grafik 1. Data OHLC AMRT 2015-2019 Monthly}

Dalam rentang 5 tahun tersebut, dengan menerapkan strategi DMAC, didapati 69 kali crossing, baik dari bawah ke atas atau pun dari atas kebawah. Dari 69 crossing tersebut, terdapat 34 (49.275\% dari total crossing) sinyal transaksi beli.

Dari 34 sinyal transaksi beli tersebut, terdapat 16 (47\%) transaksi loss, $14(41.176 \%)$ transaksi profit, dan 4 $(11.76 \%)$ transaksi break even .Sedangkan dari jumlah poin, transaksi loss 525 poin, dan transaksi profit 590 poin.Sehingga dari 16 transaksi loss, masih memperoleh profit 65 poin. Rata-rata transaksi loss 32.81 poin per transaksi, dan profit42.14poin per transaksi. Sedangkan loss paling besar 90 poin dan profit paling besar 135 poin.Jumlah loss dan break even berturutturut tanpa profit mencapai 6 transaksi, dengan total penurunan 105 poin.

Tabel 1. Overview Sinyal Transaksi

\begin{tabular}{lrrr}
\multicolumn{1}{c}{ Remarks } & Profit & Loss & BE \\
\hline Transaksi & 14 & 16 & 4 \\
Poin & 590 & 525 & - \\
Poin per Transaksi & 42.14 & 32.81 & - \\
Max Poin & 135 & -5 & - \\
Min Poin & 5 & -90 & - \\
\hline \multicolumn{1}{c}{ Berikutnya, } & berdasarkan & data
\end{tabular}
sinyal tersebut, penulis mensimulasikan trading dengan asumsi:

$$
\begin{aligned}
& \text { Lot per trx }=1(100 \mathrm{lbr}) \\
& \text { Modal awal }=\operatorname{Rp~100,000}
\end{aligned}
$$




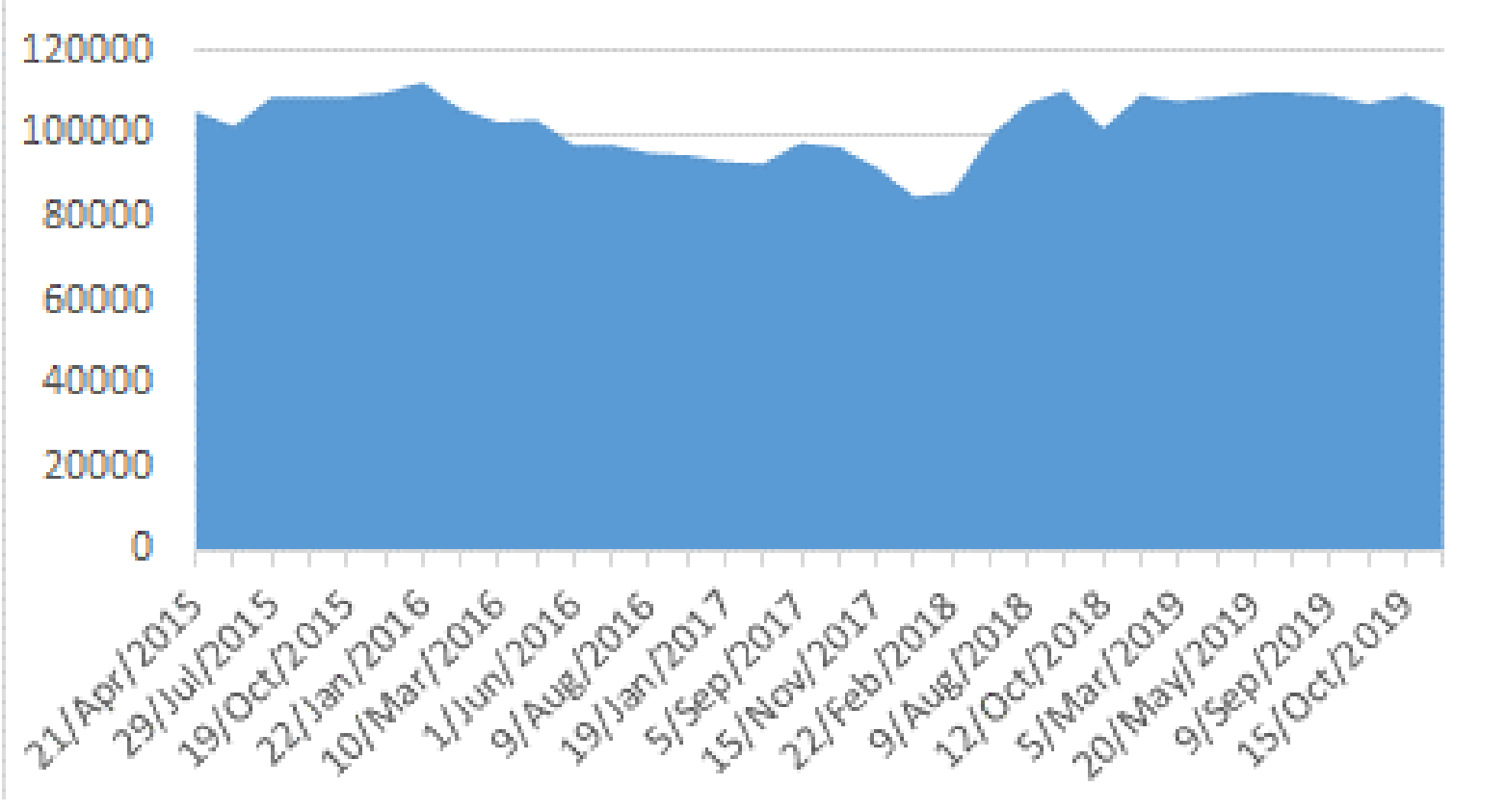

Grafik 2. Perkembangan Portofolio Simulasi

Secara keseluruhan, dengan modal awal Rp 100,000, berkembang menjadi Rp 106,500 di akhir 2019. Berarti portofolio berkembang $6.5 \%$. Perkembangan portofolio tertinggi pada 22 Januari 2016, mencapai Rp 112,500 (+12.5\% dari modal awal). Sedangkan paling rendah mencapai $\mathrm{Rp}$ 85,000 (-15\% dari modal awal) pada 12 Desember 2017.

\section{E. Simpulan}

Hasi lsimulasi di atas menunjukkan bahwa pertumbuhan harga saham AMRT selama lima tahun dari Januari 2015 hingga Desember 2019 lebih besar (390 poin) dibandingkan dengan pertumbuhan portofolio dengan menerapkan strategi DMAC (65 poin).
Penerapan strategi DMAC di atas,menghasilkan sinyal transaksi beli dengan jumlah loss lebih banyak dari profit, bahkan terdapat 6 transaksi loss yang berturut-turut yang mencapai -105 poin. Namun jumlah poin profitnya lebih banyak daripada loss. Sehingga meski frekuensi transaksi loss lebih banyak, namun masih memperoleh profit dari selisih jumlah poinnya.

Bagi peneliti berikutnya, dapat ditambahkan analisa perbandingan hasil portofolio dengan menambahkan Martingales Money Managemen tuntuk menutupi jumlah loss-nya.

Bagi investor pemula, strategi DMAC di atas terbukti menghasilkan keuntungan dari fluktuasi (naik-turunnya) 
harga. Sehingga dapat digunakan sebagai strategi alternatif selain buy-and-hold. Sehingga dapat dijadikan acuan menentukan momen yang tepat untuk masuk dan keluar pasar saham. Penggunaannya dapat dikombinasikan dengan indikator yang bersifat leading. Mengingat indicator moving average bersifat lagging. Dengan bantuan indikator yang bersifat leading, investor dapat lebih responsive dalam menindaklanjuti perubahan harga.

\section{F. Daftar Pustaka}

Abarbanell, J. S., \& Bushee, B. J. (1997). Fundamental Analysis, Future Earnings, and Stock Prices. Journal of Accounting Research, 35(1), 1. https://doi.org/10.2307/2491464

Bagus W., P. S. (2007). Options is a New Life Style. Elex Media Komputindo.

Dechow, P. (2001). Short-sellers, fundamental analysis, and stock returns. Journal of Financial Economics, 61(1), 77-106. https://doi.org/10.1016/S0304405X(01)00056-3

Deni Sunaryo, S. M. B. M. M. (2019). Manajemen Investasi dan Portofolio. CV. Penerbit Qiara Media.

Finnerty, J., Lee, C., Lee, J. C., Wort, D., \& Lee, A. C. (2012). Security Analysis, Portfolio Management, And Financial Derivatives. World Scientific Publishing Company.

Investing.com. (2020). Sumber Alfaria Trijaya Stock Dividend - Investing.com. https://www.investing.com/equities/su mber-alfaria-dividends
Kilgallen, T. (2012). Testing the Simple Moving Average across Commodities, Global Stock Indices, and Currencies. The Journal of Wealth Management, 15(1), https://doi.org/10.3905/jwm.2012.15.1. 082

Lim, M. A. (2015). The Handbook of Technical Analysis + Test Bank: The Practitioner's Comprehensive Guide to Technical Analysis. Wiley.

Mladjenovic, P. (2016). Stock Investing for Dummies. John Wiley \& Sons.

Murphy, J. J. (1999). Technical Analysis of the Financial Markets: A Comprehensive Guide to Trading Methods and Applications. Penguin Publishing Group.

Picasso, A., Merello, S., Ma, Y., Oneto, L., \& Cambria, E. (2019). Technical analysis and sentiment embeddings for market trend prediction. Expert Systems with Applications, 135, 60-70. https://doi.org/10.1016/j.eswa.2019.06. 014

Prayudha, T. (2018). Hal Paling Sulit Dilakukan Bagi Investor Saham. https://bigalpha.id/news/hal-palingsulit-dilakukan-bagi-investor-saham

Rockefeller, B. (2014). Technical Analysis For Dummies. Wiley.

Stewart, T. H. (1996). How Charts Can Make You Money: An Investor's Guide to Technical Analysis. Elsevier Science.

Tandelilin, E. (2010). Portofolio dan Investasi: Teori dan Aplikasi. Kanisius. 